\title{
Studies on Multimedia English Teaching from Students' Angle of View
}

\author{
Zefen Zhang \\ Foreign Language Department \\ Henan Institute of Science and Technology \\ Xinxiang Henan, China \\ Email address: eshui2010@163.com
}

\begin{abstract}
This paper is based on the investigation and interview methods to probe on multimedia English teaching from the students' angle of view and cognitive psychology. The author achieves results after conducting a preliminary comparison into the relationships between traditional English teaching and multimedia English teaching by investigation and interview.
\end{abstract} view

Key words-multimedia; English teaching; students; angle of

\section{Introduction}

With the rapid development of computer multimedia technology, traditional teaching way which just only depends on teachers' speaking and students' listening embodies a lot of disadvantages, it makes the class content and form be boring and monotonous, so the students fail to concentrate on it last long time and greatly influent efficiency of learning English. It is considered that seeing is the ordinary behavior for human beings but as a simple way in cultural conversion ( 周宪, 2003 ). In foreign countries, the researches about educational technology are only confined to production and application of teaching movies, videos, sound, and other kinds of media. The famous New York university psychologist Jerome Burner found that $10 \%$ of humans memory is transmitted by audition, $30 \%$ by reading while $80 \%$ by view based on his research ( Paul M. Lestm. 2003:447 ) . In China, many research papers are presented that the teaching success is only depended on interface design, image, and color. For example, Zhang Yan elaborated the relationship between colors and learning strategies in her paper Color Designing in Multimedia Courseware. However, many teachers have an intuitive feeling in making and using multimedia courseware, especially refer to visual communication design from students' angle of view. There is no doubt that few people combine the students vision and the multimedia English teaching to study further, but in general people become to realize that it is a long march to come true the promotion of students' cognition psychology.

\section{The Visual Transmission}

\section{A The Connotation and Features of Visual Transmission Design \\ 1) Connotation of Visual Transmission Design}

It is wildly adapted that visual culture we named could arouse students' imagination and encourage our emotion ripples, which is a kind of manifestation of visual information and can be visualized by perceptual organs(Fenhong Dai, 2004:74-76). Visual communication design is by means of the visual marks to convey information, for example, graphics, characters, colors and especially the visual images play a main role in the visual perception, which stimulates people's psychological reflection to realize the information transmission function.

Information is the carrier of human interaction and the subject of design. A series of forms on information communication use words, symbols, music, digits, graphics and other forms of expression, but in general can be divided into two kinds of parts, namely — visual and sound. Vision is the picture information that can be perceived and received, as soon as the picture information visualized by eyes; this is what the visual communication design to study and plan. Transmission is a kind of information communication or information exchange when we undertake to design information. The process demands that we not only consider convenience, accuracy and effectiveness, but also concern the target public.

\section{2) Features of Visual Transmission Design}

There are many forms about visual information, such as symbol and text. Human beings have created all kinds of methods for recording information, different expression methods rely on a variety of visual elements. There are five features in transmission design: the first is the symbol, symbol is the longest visual expression in history and concise, lively, recognizable and easy to memorize; the second is the character, as the communication tool and abstract symbol, the characters are most frequently used in our daily life. Although the character is abstract, it has a flexible writing style, which is widely recognized by public; the third is graphic, visual transmission design makes full use of graphics to transmit information except for using the character as a carrier to exchange ideas that we are familiar with; the fourth is image, which is an indispensable element of visual communication design is capable to enhance the reliability of design and provide assurance of information expression accurately; the last one is color, information can reflect objective world truthfully, different subjects and contents should be taken in different colors to show. In terms of the selection of colors, we must be clear of the target task the colors used, namely the role of color is an auxiliary communication. 


\section{B The Application and Principles Designing of Visual Transmission}

\section{1) The Application of Visual Transmission}

English as an applied language is not as same as the image. There are three most prominent visual features about language; linear, orderly, abstract. Language represents an important form of rational culture of human culture. English teaching is a complex and multidimensional process, involving the language function, language points, literature, cultural communication, psychology and sociology etc... For the English teaching, teaching forms, method, learning environment and the dynamic factors are the more important, especially the students' learning motivation and learning interest largely determine the effect of English teaching. Multimedia courseware in English teaching provides an intuitive and efficient new way.

Multimedia courseware combines computer technology with art, adopting the vivid image, beautiful picture, so that the information acquisition and transmission express more appealing and artistic, this edutainment arouses the students' interest and improve students' learning enthusiasm. Interest is the best teacher. Interest and motivation make them change passive learning into active learning. If multimedia coursewares are used in English teaching, learning environment can be greatly improved in English learning, it drives the students to learn English consciously, and become the seekers of knowledge. In traditional English teaching, the teacher's oral speaking occupies most of time, making students feel bored and failing long time to concentrate on.

To learn English well, the key is to practice, because language is inseparable from the context. In traditional English teaching, the teachers let the student be in the hypothetical situation just only by description. This method often makes students easily forget, and lead to syntax errors. While the use of pictures displayed in multimedia courseware set different situational context. On seeing this, students can easily associate with corresponding English expression. Multimedia coursewares change from rigid illustrations to dynamic pictures or activities, so it seems that the students' association will become richer, and the memory will be more profound because of intuition.

\section{2) Principles Designing of Visual Transmission}

Multimedia courseware visual elements mainly consist of color and caption. Compared with the traditional teaching method, the use of multimedia courseware shows great advantages in the teaching process. Therefore, the design of multimedia courseware should fully embody the advantages and abide by the following four principles from students' visual sense: the first is intuition principle, which reflects the intuitive understanding for students and supplies a vivid, specific image of abstract knowledge; the second is interaction principle. Multimedia English teaching has diversified classroom information between teachers and students. English teaching needs a consistent communication process from multi-angle, so teachers must choose proper audio-visual materials, such as English movies and songs, local customs. It can not only enrich the students' knowledge, cultivate speech accent but also more importantly it makes English teaching no longer simply rely on teachers, students' answering and exercises, so as to achieve purpose of communication and feedback; the third is interest principle, foreign language curriculum is a skill training and practice course essentially. We should mobilize all the senses of students to let them in a teaching situation based on their psychological characteristics so as to help students arouse their interest and establish their confidence during the cognitive process, which lay the foundation for them to learn English well; the last one is pertinence principle. Multimedia English teaching reflects the people-oriented teaching idea, which in beneficial for students' individual learning, because its purpose aims to simplify key and difficulties.

\section{The Existing Visual Advantages}

\section{A Communication Tool}

Language learning needs the language environment, while the use of multimedia is a better choice currently for creating the language environment, it can fully arouse students' visual and other sensory organs as a good method, thereby obtaining excellent cognitive effect. Cognitive psychology research shows that, the $94 \%$ information human is transmitted largely by the visual and auditory organs, in which $82 \%$ by vision and $12 \%$ by audition ( ibid ). It means that the visual organ is one of the most important learning organs. The image information provides synchronism for students with a controlled wide channel. In addition, communication which needs background information is a two-way psychological process. The background factor is an essential aspect in culture. We make full use of multimedia to supply some foreign cultural backgrounds to English learners, such as western history, life ways and folk customs, especially for English-speaking countries. When we desire to get to know and learn Shakespeare, it allows students to learn about his life and Western architectural style by displaying pictures of Shakespeare's experiences and his former residence, which extends the students view from the class to foreign countries without stepping out class. So as to further make sense of the mystery of the western countries. They lay an excellent foundation between students and teachers, and promote their communication in English class.

\section{B Demonstration Tool}

English teaching can not push classroom teaching to the climax if only rely on the teachers' elaboration, which requires the multimedia to play its demonstration effect using this advanced technology. In order to effectively illustrate the text issues, teachers often need to collect English teaching materials via movies, television, video, Internet and then demonstrate to the students at the right time.

Vocabulary learning is relatively tedious in English classroom, the traditional method asks students to read after teachers or cassette tape, which can fail to stimulate students' comprehensive sense effectively and completely. The application of multimedia courseware with acoustic and luxuriant images will give the students a new feeling and their excitement was mobilized, so as to make the words learning become an easy job. As to learn the new word "Director", we can download the foreign and Chinese famous directors' 
pictures. On seeing these, we could easily recognize these directors and indulge in associating with the Hollywood, Oscar and other words, then ask students to repeat two times to make the student master the basic words, which will help students to clean obstacles for studying the following sentences and text. Considering the cognitive psychology, it changes the boring text content into an intuitive image and arouses the students' interest and enthusiasm of the students positively under the help of multimedia courseware.

\section{Writing Tool}

A blog is a website and it often consists of simple and often updated posts which are all sequenced according to year and date. The contents and purposes of blog differ greatly. They rang from news about companies, individuals to diaries, photos, poems, poses even the publication of scientific fictions. Bloggers are those that write web logs or blogs. Blog used in the teaching of English writing breaks the traditional English teaching model. Using blog as a new kind of teaching methods help students master a modern kind of English writing tool and stimulate students' writing interest. Teachers offer favorable help, and allow students to write compositions and hand in their compositions in their own blogs, which greatly enhance students' writing interest. Students making use of computer to write compositions can make students more suitable to modern life, meanwhile, the functions of computer like typesetting, revision, spelling and grammar examination let students further improve their own tasks and save teachers' lots of time in correcting unimportant mistakes in students' compositions to a large extent.

\section{Supplying a Concrete Learning Situation}

The first problem is difficult to focus attention to the classroom for students under the influence of visual culture, multimedia takes advantage of the visual impact to drive students emerge from the break to concentrate on the class quickly, in order to concentrate full of confidence to participate in teaching activities energetically. Multimedia English Teaching set up the approximately real or virtual language environment for the students, providing them with sufficient English practice and communication opportunities. In English teaching, according to the characteristics of teaching materials and practical needs, multimedia creates a certain situation to let the student experience and make inquiries in these plot, especially understand the thing itself in particular context. According to the principles of communication, multimedia plays a positive role in arousing students' interests, creating the social environment. It is helpful to promote mass communication activities with students as the center in the English teaching so as to let students fully experience the teaching process of communication, thereby creating a natural dialogue communication conditions.

\section{E Highlighting the Key Points}

The usage of multimedia makes the abstract things into the concrete images, and strong emphasis key points and difficulties on the screen by PPT. By means of the modern education technology, it can offset for the defects of traditional education effectively, which is taken to mobilize students' visual function and create a good atmosphere for highlighting the keystone. Take English learning for example, we can use the red color to underline what we take account of the text.

\section{The Existing Visual Problems}

\section{A Lack of Creative Design of Materials}

In order to reduce the lesson preparation and simplify preparation procedure, a majority of teachers just copy teaching materials text on a computer screen when designing multimedia courseware, it becomes entirely the expression of the electronic version in the content arrangement and certainly ignores the students' visual perception. It is widely considered that multimedia courseware is just "electronic" performance. Also most teachers only take a single method "PowerPoint", with a template in the multimedia courseware design. As a consequence, the students are no longer interested in multimedia courseware transmission in learning process or even produce bored feeling, which is not conducive to teaching activities smoothly.

\section{B Lack of Verbal Communication}

As a presentation tool and intuitive information, multimedia technology has to replace the dominant position of the teacher as a result of soaring of multimedia. It is clearly that excessive emphasizing the role of multimedia will change the status of teachers in the classroom, so sometimes we can see teachers do not write, do not think, also do not need to say more, just do it as a courseware operator, instead of the teacher's guidance and teaching, Teachers begin to lose their dominant position just like tour guides, as the core-oriented body, it is likely that the students play the role of audience in the theatre of whole class gradually, and no longer be the participants of teaching activities definitely. So it is easy to cause a serious "lack of language communication". Some students reflect that the teachers indulge into the mouse, keyboard and screen and become a computer operator and the narrator instead of having more time and energy to pay attention to the students, causing verbal loss between the teachers and students. In terms of the students, most of their attention is focused on the electronic screen without opportunities to think and speak. If there are no speaking interactions between teachers and students, it can also cause visual fatigue and mental weariness of students and affect their learning enthusiasm.

\section{Too Much Information Making Students Confused}

Computer is capable of storing large amounts of information. Therefore, teachers take full advantages in order to list all relative materials efficiently when they make courseware. But sometimes teachers have to accelerate the speed of outputting information because of time restrictions in classroom. So it is difficult for students to grasp the difficulties and important information they face. When the screen speed appears too quickly, the student is too busy to follow, especially the inferior students are unable to concentrate on and come with the rhythm of teaching, and even give up listening continuously which will affect students' confidence and effect. 
D Failure of Supporting Combinations of Color, Words, Sound and Shape

The courseware gets rid of visual sense beauty without considering interface, font and colors design. Other teachers attach too much importance on multimedia courseware design and pursue the rich forms excessively like practical graphics, video, color and other elements, resulting in the display information being too rich and complicated and drive students to appreciate the picture while dispersing the attention to others. It will make the students lose interest in learning, and even produce anxiety so that influent learning quality. Secondly, color collocation is unreasonable. Color contrast of multimedia course can attract students' attention, which will reduce information transmission effectiveness and make students feel bored if we excessively pay more attention to it.

\section{Analysis and Countermeasures}

In the multimedia courseware, the role of subtitle is to rearrange key contents in order to make them more coherent, thus the letter design is essential. First of all, it should be easy to read. Word density should be moderate and standardized. It is hard to select information and produce visual noise if the computer windows contain too much information. Secondly, subtitle design is related to key points. It is clear that speed change of caption color and size are associated with learners' attention to highlight the key points. If the subtitle size is large, students are able to make a distinction between title and content. Thirdly, letter design also emphasizes the stability.

Color as a kind of visual element structure the visual interface, so it asks its choice must not only conform to the teaching subject, but also fits the requirement of aesthetic appreciation. Firstly color tone should be identical to the teaching content. After all, right choice not only benefits to the expression of teaching content, but also be conducive to the creation of the teaching situation, so that learners seem to place themselves in real situations. Secondly, the choice of color should be consistent with the learners' age characteristics. For example, children love very bright colors; teenagers like bright warm colors, such as yellow, orange, and pink; the older prefer to dull color. Thirdly, the foreground and background collocation should be easy to read. Foreground and background in color must have distinct distinction to show the contrast of light and shade. But the contrast could not be too strong; otherwise it will easy to produce visual fatigue.

\section{Conclusion}

With the soaring of computer, the multimedia courseware has stepped into classroom, the new technique plays a special role in changing the traditional teaching and learning situation, in relaxing the atmosphere in the classroom, in creating an appropriate learning environment, as well as in triggering out interest in studying.

The paper introduces realization of assisting function of multimedia in English performing and communication, creating certain situation and demonstration, emphasizing both important and difficult points under the help of visual transmission design. Still, there are many problems exiting in English teaching with multimedia. For example, some teachers change the screen speed quickly, ignoring the students' visual perception totally. We should take advantages of multimedia technology in combining language with colorful pictures, animations and sound to cultivate the learning for English words, grammatical structures, and sentences.

\section{Bibliography}

[1] Beatty. Teaching and Researching Computer-Assisted Language Learning [M]. London Press, 2003.

[2] Kenneth T.Henson \& Ben F. Eller. Educational Psychology for Effective Teaching [M]. Beijing : Foreign Language Teaching and Research Press, 2005.

[3] Arthur Arthur Berger. Seeing is Believing - Visual Communication[M]. Nanjing: Jiangsu Fine Arts Publishing House, 2008, 2.

[4] Fenhong Dai, Yue-hong Sun. Vision Culture in the Multimedia Courseware[J]. Journal of Hebei Energy Institute of Vocation and Technology, 2004(12):75-76.

[5] Han Bing. Visual Culture of Multimedia Courseware in English Teaching $[\mathrm{J}]$. The Guide of Science \& Education, 2003, 6.

[6] Hong Song. Instruction on English Vocabulary Learning Strategies Based on Multimedia [J]. Huazhong Normal University Journal of Postgraduates, 2006, 6.

[7] Meng Jian. Image Time: Theoretical Analysis of Visual Culture Communication [M]. Shanghai: Fudan University Press, 2005.

[8] Paul M. Lestm. Visual Communication: Image Carrying Information [M]. Wenli Huo, Xueyun,Shi, Hairu Wang transl. Beijing: Beijing Broadcasting Institute Press, 2003(447).

[9] Wang Qi. Research on University English Multimedia Network Teaching [J]. Overseas English, 2010, 5.

[10] Wang Qiang. English Teaching Method Course ( Second Edition ) [M]. Beijing: Higher Education Press, 2006, 5.

[11] Qiaoling Xiao. Multimedia English Teaching Based on Constructivism[J]. Journal of Wuhan University of Science and Technology(Social Science Edition), 2007, 9.

[12]Zhou Ling. Present Situation of Multimedia English Teaching and Countermeasure in Primary and Secondary Schools - a Case Study of Ping Ding Shan City [J]. Journal of Educational Institute of Jilin, 2011, 3.

[13]Zhou Xian. Visual Culture: from Tradition to the Modern [J]. Literature Review, 2003, 6.

[14]Haiyan Zhang. An Empirical Study of University English Writing Teaching Based on Blog [J]. Journal of Changchun University of Science and Technology(Social Science Edition), 2011, 5. 